Proceedings of the International Conference on Oxide Materials for Electronic Engineering, May 29-June 2, 2017, Lviv

\title{
Synthesis and Vibration Spectroscopy of Nano-Sized Manganese Oxides
}

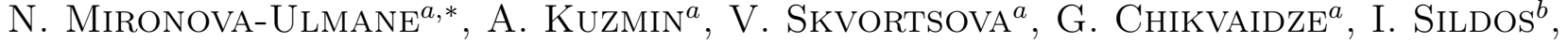 \\ J. GRABis ${ }^{c}$, D. JANKOVIČA ${ }^{c}$, A. Dindune ${ }^{c}$ And M. MAIOROV ${ }^{d}$ \\ ${ }^{a}$ Institute of Solid State Physics, University of Latvia, Kengaraga Str. 8, LV-1063 Riga, Latvia \\ ${ }^{b}$ Institute of Physics, University of Tartu, W. Ostwaldi tn 1, 50411 Tartu, Estonia \\ ${ }^{c}$ Institute of Inorganic Chemistry, Riga Technical University, P. Valdena Str. 3/7, LV-1048 Riga, Latvia \\ ${ }^{d}$ Institute of Physics, University of Latvia, Miera Str. 32, LV-2169 Salaspils, Latvia
}

\begin{abstract}
X-ray diffraction, micro-Raman and the Fourier transform infrared spectroscopies as well as magnetometry measurements were performed on nanosized manganese oxides to probe their phase composition and magnetic properties. It was shown that the XRD method is less sensitive to phase composition of manganese oxide samples than spectroscopic methods. While in some samples the XRD method recognised only the manganosite MnO phase, the Raman and FT-IR methods revealed additionally the presence of the hausmannite $\mathrm{Mn}_{3} \mathrm{O}_{4}$ phase.
\end{abstract}

DOI: $10.12693 /$ APhysPolA.133.1013

PACS/topics: 81.07.Wx, 61.05.cp, 78.30.Hv, 75.30.Cr

\section{Introduction}

Manganese oxides are widely used as supercapacitor electrode materials [1] and catalysts [2], for the preparation of $\mathrm{Li}-\mathrm{Mn}-\mathrm{O}$ electrodes for rechargeable lithium batteries $[3,4]$ and of soft magnetic materials such as manganese zinc ferrite, which is applicable as magnetic cores in transformers for power supplies [5]. The manganosite $\mathrm{MnO}$ phase (space group Fm3m) is a Mott insulator ordering antiferromagnetically below approximately $118 \mathrm{~K}$ [6]. Magnetostructural phase transitions in $\mathrm{MnO}$ antiferromagnets were studied by high-precision neutron diffraction [7]. It was shown that the structural and magnetic transitions in polycrystalline $\mathrm{MnO}$ occur synchronously, and their temperatures coincide within the experimental errors: $T_{s t r} \approx T_{m a g} \approx(119 \pm 1) \mathrm{K}$ [7]. While being studied for a long time, $\mathrm{MnO}$ still attracts considerable interest, which has been extended recently to its nanostructures $[8,9]$. It is known that the magnetic properties of $\mathrm{MnO}$ are strongly affected by the presence of $\mathrm{Mn}_{3} \mathrm{O}_{4}$ impurity phase, being ferrimagnetic below approximately $43 \mathrm{~K}[10] . \quad \mathrm{Mn}_{3} \mathrm{O}_{4}$ has the normal spinel structure with general formula $\mathrm{A}^{2+} \mathrm{B}_{2}^{3+} \mathrm{O}_{4}^{2-}$. At room temperature, it has tetragonal hausmannite (space group $I 4_{1} / a m d$ ) phase with $\mathrm{Mn}^{3+}$ and $\mathrm{Mn}^{2+}$ ions occupying the octahedral (B-sites) and tetrahedral (A-sites) positions of the spinel structure, respectively. The $\mathrm{MnO}_{6}$ octahedra are tetragonally distorted due to the JahnTeller effect on $\mathrm{Mn}^{3+}$ ions [11]. Thus, the ionic formula of $\mathrm{Mn}_{3} \mathrm{O}_{4}$ is often written in spinel notation as $\mathrm{Mn}^{2+}\left[\mathrm{Mn}_{2}^{3+}\right] \mathrm{O}_{4}$.

*corresponding author; e-mail: nina@cfi.lu.lv
In this study the sensitivity of several experimental methods as X-ray diffraction (XRD), micro-Raman and Fourier transform infrared (FT-IR) spectroscopies as well as magnetometry measurements to the presence of $\mathrm{Mn}_{3} \mathrm{O}_{4}$ impurity in manganosite $\mathrm{MnO}$ phase was investigated.

\section{Experimental}

The manganese oxides nanoparticles were synthesized by hydrothermal method. $0.5 \mathrm{M}$ of cetyltrimethylammonium bromide $(\mathrm{CTAB})$ was dissolved in $80 \mathrm{ml}$ of ethanol. The CTAB buffer extraction was done immediately before use since it is required that the buffer should be freshly prepared. Next, the manganese acetate was added and dissolved. After that glycerol and nitric acid were added at the temperature of $350 \mathrm{~K}$, stirred by magnetic stirrer and evaporated completely. The resulting powder product was loaded in a preheated to $620^{\circ} \mathrm{C}$ furnace and heated at $720^{\circ} \mathrm{C}$ for $2 \mathrm{~h}$ in a vacuum. As a result, the first sample, labelled as $\mathrm{MnO}(\mathrm{I})$, was obtained. The second sample, labelled as $\mathrm{MnO}$ (II), was obtained by heating at $720^{\circ} \mathrm{C}$ for $2 \mathrm{~h}$ in a mixed argon and hydrogen atmosphere instead of vacuum.

The XRD patterns of the nanosized powders were recorded at room temperature using a Bruker ADVANCE D8 $\theta-2 \theta$ diffractometer equipped with a copper anode tube $\left(\mathrm{Cu} K_{\alpha}\right.$ radiation $)$ in the range of $2 \theta=10-100^{\circ}$ with the angular step size $0.01^{\circ}$ and the scan speed $0.3^{\circ} / \mathrm{min}$.

Micro-Raman scattering spectra were measured in the backscattering geometry at room temperature through $20 \times$ and $50 \times$ objectives using a Renishaw inVia microRaman spectrometer equipped with an argon laser (488 nm, maximal $\mathrm{cw}$ power $P_{e x}=50 \mathrm{~mW}$ ) and through $40 \times$ objective using a confocal spectrometer NanofinderS (SOLAR TII, Ltd.) equipped with a DPSS laser 
(532 nm, maximal cw power $P_{e x}=150 \mathrm{~mW}$ ). The spectral signal was dispersed by 2400 or 600 grooves $/ \mathrm{mm}$ gratings onto Peltier-cooled CCD detectors.

Infrared spectra were measured using the $\mathrm{KBr}$ pellet method in the energy range from 200 to $800 \mathrm{~cm}^{-1}$ employing a vacuum FT-IR Bruker VERTEX 80v spectrometer equipped with a closed-circle optical helium cryostat.

The temperature dependences of the oxide magnetic properties (specific susceptibility) were measured using a vibrating sample magnetometer (Lake Shore Cryotronic Co., Model 7404 VSM) equipped with the single-stage variable temperature option.

\section{Results and discussion}

The crystallinity and phase composition of both $\mathrm{MnO}(\mathrm{I})$ and $\mathrm{MnO}(\mathrm{II})$ samples were investigated by $\mathrm{X}$ ray powder diffraction. Their XRD patterns are shown in Fig. 1. The XRD pattern of $\mathrm{MnO}(\mathrm{I})$ corresponds to a pure face-centred cubic $\mathrm{MnO}$ phase (mineralogical name manganosite, JCPDS Card 00-075-1090), which is isostructural with $\mathrm{NaCl}$. No additional peaks due to any impurity phase are observed. The obtained lattice parameter of $\mathrm{MnO}$ is $a=4.46 \AA$, and the average crystallite size is $55 \mathrm{~nm}$. The peaks in the XRD pattern of $\mathrm{MnO}$ (II) sample are broader than for $\mathrm{MnO}$ (I) sample due to smaller average crystallite size, and, additionally, the XRD pattern contains a contribution from impurity phase $\mathrm{Mn}_{3} \mathrm{O}_{4}$ (mineralogical name hausmannite). The lattice parameters of $\mathrm{MnO}$-manganosite (average crystallite size is $22 \mathrm{~nm}$ ) and $\mathrm{Mn}_{3} \mathrm{O}_{4}$-hausmannite (average crystallite size is $14 \mathrm{~nm}$ ) phases in $\mathrm{MnO}$ (II) sample agree well with those for bulk crystals: $a=4.45 \AA$ (JCPDS Card $00-075-1090)$ and $a=5.7621 \AA, c=9.4696 \AA$ (JCPDS Card 01-080-0382), respectively.

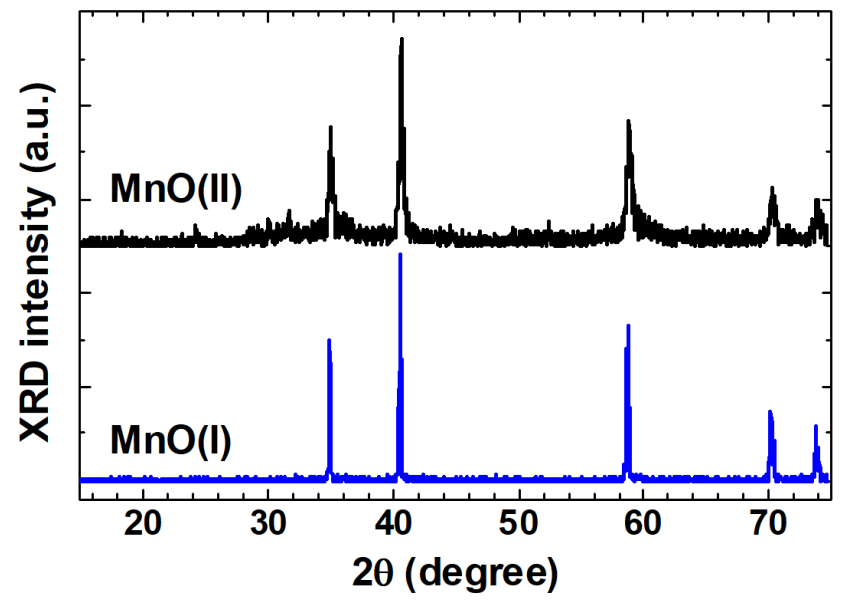

Fig. 1. X-ray diffraction patterns of manganese oxide samples.

Micro-Raman scattering spectra of $\mathrm{MnO}(\mathrm{I})$ and $\mathrm{MnO}(\mathrm{II})$ samples are shown in Fig. 2. Pure MnO has at room temperature the cubic rock-salt structure, and, thus, it should not exhibit any first-order Raman activity. The Raman scattering spectra of both samples contain a strong narrow band at $660 \mathrm{~cm}^{-1}$ and two small bands at about 318 and $370 \mathrm{~cm}^{-1}$, indicating the presence of hausmannite $\mathrm{Mn}_{3} \mathrm{O}_{4}$ phase [11-14]. Detailed assignments of theoretically computed Raman modes of $\mathrm{Mn}_{3} \mathrm{O}_{4}$ can be found in [11]. The Raman spectrum of $\mathrm{MnO}(\mathrm{I})$ sample contains additionally two broad asymmetric bands at about 530 and $1050 \mathrm{~cm}^{-1}$. The low frequency band at $530 \mathrm{~cm}^{-1}$ has been attributed previously to 2TO $[15,16]$ or LO [17] phonons in manganosite $\mathrm{MnO}$ phase. The high frequency band at $1050 \mathrm{~cm}^{-1}$ has complex origin: it envelops two bands related to the $\mathrm{TO}+\mathrm{LO}$ (a band wing at $950 \mathrm{~cm}^{-1}$ ) and 2LO modes [17] in manganosite $\mathrm{MnO}$ phase. The intermediate band due to the $2 \mathrm{TO}$ modes has a weak intensity and is masked by a narrow band contribution at $660 \mathrm{~cm}^{-1}$ due to the $\mathrm{Mn}_{3} \mathrm{O}_{4}$ phase. Such assignments agree well with the results of the inelastic neutron scattering [18] and recent first-principles theoretical calculations [19], which give the zone-centre phonon modes $\omega(\mathrm{TO}) \approx 280 \mathrm{~cm}^{-1}$ and $\omega(\mathrm{LO}) \approx 497 \mathrm{~cm}^{-1}$. The obtained results also agree with those for single-crystal $\mathrm{MnO}$ and $\mathrm{Mn}_{3} \mathrm{O}_{4}$ samples [17], which were epitaxially grown by the chemical transport reactions method from polycrystalline $\mathrm{MnO}$ source on $\mathrm{MgO}$ (100) substrate.

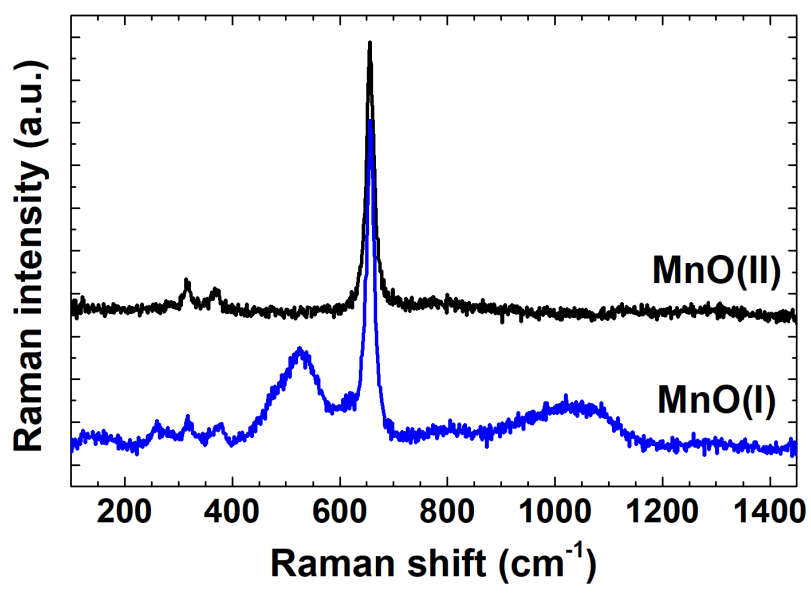

Fig. 2. Micro-Raman scattering spectra of manganese oxide samples.

The infrared spectra of $\mathrm{MnO}(\mathrm{I})$ and $\mathrm{MnO}(\mathrm{II})$ samples in the far-red range of $230-650 \mathrm{~cm}^{-1}$ are shown in Fig. 3 and are composed of several strongly overlapped bands. The spectrum of $\mathrm{MnO}(\mathrm{I})$ sample consists of a broad band at $285 \mathrm{~cm}^{-1}$ attributed to manganosite $\mathrm{MnO}$ phase, and four bands at 420,480, 510, and $600 \mathrm{~cm}^{-1}$ attributed to hausmannite $\mathrm{Mn}_{3} \mathrm{O}_{4}$ phase [11, 20]. The spectrum of $\mathrm{MnO}$ (II) sample consists of three main bands at 257,382 , and $490 \mathrm{~cm}^{-1}$ and two weak bands at 434 and $602 \mathrm{~cm}^{-1}$, which can be attributed to hausmannite $\mathrm{Mn}_{3} \mathrm{O}_{4}$ phase $[11,20]$. Note that three bands at 407, 502, and $620 \mathrm{~cm}^{-1}$ were reported in the literature for $10 \mathrm{~nm}$ $\mathrm{Mn}_{3} \mathrm{O}_{4}$ nanoparticles [13]. 


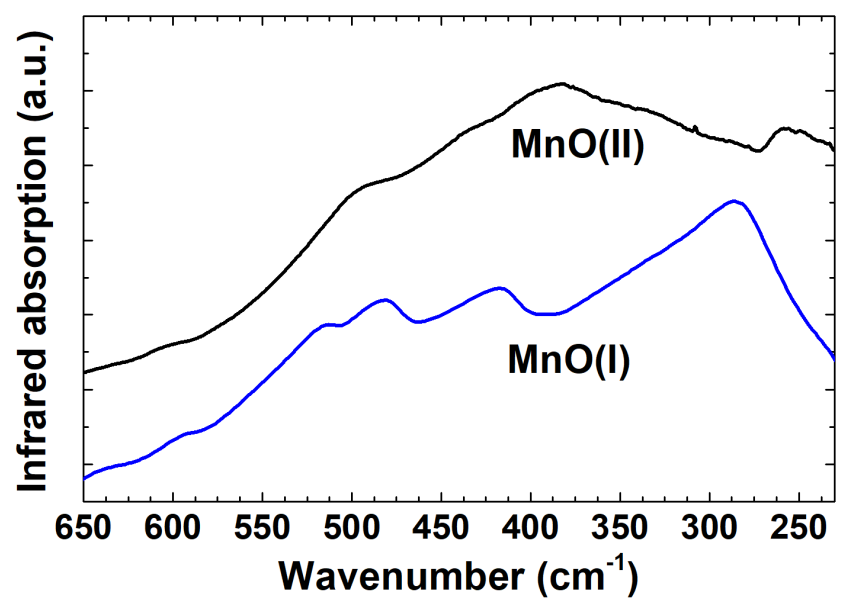

Fig. 3. Infrared spectra of manganese oxide samples.

The magnetic properties of $\mathrm{MnO}(\mathrm{I})$ and $\mathrm{MnO}(\mathrm{II})$ samples were investigated by magnetometry measurements. Magnetic susceptibility of an antiferromagnet should increase with temperature rise up to the Néel temperature and then decrease following the Curie-Weiss law. The temperature dependences of the magnetic susceptibility for both nanocrystalline samples are shown in Fig. 4: they have a particular behaviour at $120 \mathrm{~K}$, corresponding to the Néel temperature of manganosite MnO. However, temperature dependences for both samples do not follow the expected one for pure $\mathrm{MnO}$ [21]. The behaviour of magnetic susceptibility deviates from the expected one below the Néel temperature for $\mathrm{MnO}(\mathrm{I})$ sample and at all temperatures for $\mathrm{MnO}$ (II) sample. Such behaviour is evidently due to the presence of the hausmannite $\mathrm{Mn}_{3} \mathrm{O}_{4}$ phase.

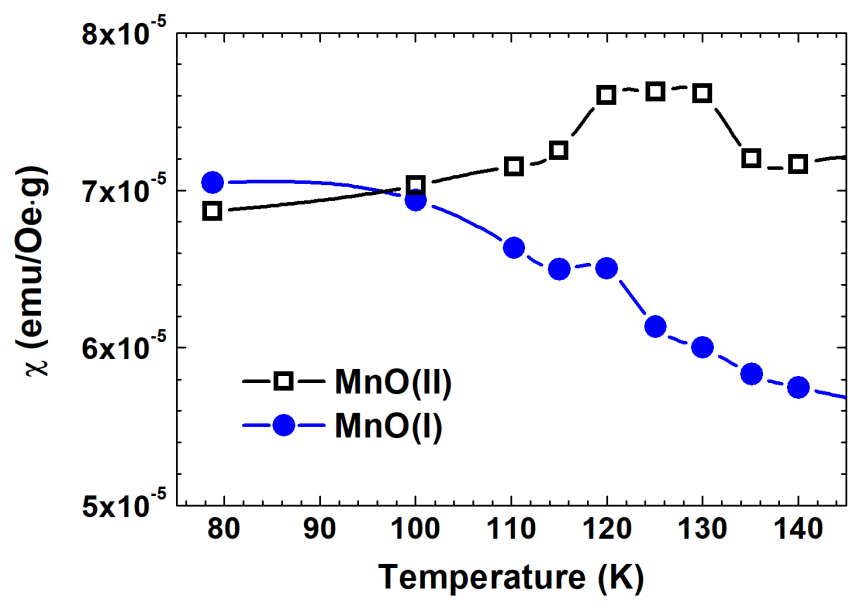

Fig. 4. Temperature dependence of the specific susceptibility of manganese oxide samples.

\section{Conclusions}

Nanocrystalline $\mathrm{MnO}$ samples with the average crystallite size of 22 and $55 \mathrm{~nm}$ were synthesized by hydrothermal method and studied by X-ray diffraction, micro-Raman and FT-IR spectroscopies to evaluate their structure and phase composition. The magnetic properties of samples were probed by magnetometry measurements.

Our results indicate that impurity hausmannite $\mathrm{Mn}_{3} \mathrm{O}_{4}$ phase is always present in the samples but its amount can be controlled by choosing annealing atmosphere. In particular, the annealing of manganese oxide in vacuum leads to significantly reduced amount of $\mathrm{Mn}_{3} \mathrm{O}_{4}$ phase, which is not observed by XRD but is detectable by Raman and FT-IR methods. At the same time, the annealing in mixed argon and hydrogen atmosphere results in a larger amount of impurity $\mathrm{Mn}_{3} \mathrm{O}_{4}$ phase, which can be detected also by XRD. Thus, we have shown that the Raman and FT-IR spectroscopies are more sensitive to the presence of $\mathrm{Mn}_{3} \mathrm{O}_{4}$ phase than X-ray diffraction method.

The transition from the antiferromagnetic state to the paramagnetic state was observed for both nanocrystalline $\mathrm{MnO}(\mathrm{I})$ and $\mathrm{MnO}$ (II) samples using the magnetic susceptibility measurements at the temperature of $120 \mathrm{~K}$, which corresponds to the Néel temperature of manganosite.

\section{Acknowledgments}

The present study has been supported by the Latvian National Research Program IMIS2. One of us, IS, was supported by MES RF RFMEFI61615X0064.

\section{References}

[1] L. Zhang, T. Wei, W. Wang, X.S. Zhao, Micropor. Mesopor. Mater. 123, 260 (2009).

[2] V. Iablokov, K. Frey, O. Geszti, N. Kruse, Catal. Lett. 134, 210 (2010).

[3] A.R. Armstrong, P.G. Bruce, Nature 381, 499 (1996).

[4] N. Yabuuchi, S. Komaba, Sci. Technol. Adv. Mater. 15, 043501 (2014).

[5] S.E. Jacobo, S. Duhalde, H.R. Bertorello, J. Magn. Magn. Mater. 272-276, 2253 (2004).

[6] C.G. Shull, J.S. Smart, Phys. Rev. 76, 1256 (1949).

[7] A.M. Balagurov, I.A. Bobrikov, S.V. Sumnikov, V.Yu. Yushankhai, N. Mironova-Ulmane, JETP Lett. 104, 88 (2016).

[8] W.-M. Chen, L. Qie, Y. Shen, Y.-M. Sun, L.-X. Yuan, X.-L. Hu, W.-X. Zhang, Y.-H. Huang, Nano Energy 2, 412 (2013).

[9] J. Feng, Y. Liang, H. Wang, Y. Li, B. Zhang, J. Zhou, J. Wang, T. Regier, H. Dai, Nano Res. 5, 718 (2012).

[10] A.E. Berkowitz, G.F. Rodriguez, J.I. Hong, K. An, T. Hyeon, N. Agarwal, D.J. Smith, E.E. Fullerton, Phys. Rev. B 77, 024403 (2008).

[11] T. Larbi, K. Doll, T. Manoubi, J. Alloys Comp. 688, 692 (2016). 
[12] F. Buciuman, F. Patcas, R. Craciun, D.R.T. Zahn, Phys. Chem. Chem. Phys. 1, 185 (1999).

[13] X. Li, L. Zhou, J. Gao, H. Miao, H. Zhang, J. Xu, Powder Technol. 190, 324 (2009).

[14] M. Ristic, S. Music, S. Popovic, D.J. Dragčevic, M. Marciuš, M. Ivanda, J. Mol. Struct. 1044, 255 (2013).

[15] H.-H. Chou, H.Y. Fan, Phys. Rev. B 13, 3924 (1976).

[16] Y. Mita, Y. Sakai, D. Izaki, M. Kobayashi, S. Endo, S. Mochizuki, Phys. Status Solidi B 223, 247 (2001).

[17] N. Mironova-Ulmane, A. Kuzmin, M. Grube, J. Alloys Comp. 480, 97 (2009).
[18] E.M.L. Chung, D. McK. Paul, G. Balakrishnan, M.R. Lees, A. Ivanov, M. Yethiraj, Phys. Rev. B 68, 140406 (2003).

[19] U.D. Wdowik, D. Legut, J. Phys. Condens. Matter 21, 275402 (2009).

[20] C.M. Julien, M. Massot, C. Poinsignon, Spectrochim. Acta A 60, 689 (2004).

[21] T.R. Mcguire, R.J. Happel, J. Phys. Rad. 20, 424 (1959). 